\title{
Sex in Context: Limitations of Animal Studies for Addressing Human Sex/Gender Neurobehavioral Health Disparities
}

\author{
${ }^{-}$Lise Eliot ${ }^{1}$ and ${ }^{-S}$ Sarah S. Richardson ${ }^{2}$ \\ ${ }^{1}$ Department of Neuroscience, Chicago Medical School, Rosalind Franklin University of Medicine and Science, North Chicago, Illinois 60064, and ${ }^{2}$ Department of the \\ History of Science, Committee on Degrees in Studies of Women, Gender, and Sexuality, Harvard University, Cambridge, Massachusetts 02138
}

Many brain and behavioral disorders differentially affect men and women. The new National Institutes of Health requirement to include both male and female animals in preclinical studies aims to address such health disparities, but we argue that the mandate is not the best solution to this problem. Sex differences are highly species-specific, tied to the mating system and social ecology of a given species or even strain of animal. In many cases, animals poorly replicate male-female differences in brain-related human diseases. Sex/gender disparities in human health have a strong sociocultural component that is intimately entangled with biological sex and challenging to model in animals. We support research that investigates sex-related variables in hypothesis-driven studies of animal brains and behavior. However, institutional policies that require sex analysis and give it special salience over other sources of biological variance can distort research. We caution that the costly imposition of sex analysis on nearly all animal research entrenches the presumption that human brain and behavioral differences are largely biological in origin and overlooks the potentially more powerful social, psychological, and cultural contributors to male-female neurobehavioral health gaps.

Key words: anxiety and depression; gender; health disparities; NIH; pain; SABV; sex difference

\section{Introduction}

The diagnosis of many neuropsychiatric diseases, including autism, attention deficit hyperactivity disorder, stuttering, addiction, depression, anxiety, eating disorders, and chronic pain syndromes is markedly different between males and females. Advocates of the new National Institutes of Health (NIH) policy requiring investigators to examine sex effects in preclinical research argue that this mandate will lead to better understanding and treatment of such disorders. We avidly support welldesigned animal research that is specifically aimed at studying sex differences and sex-related variables such as gonadal hormones and $\mathrm{X}$ chromosome dosage. We also support full transparency in reporting of animal sex for the purpose of enhancing reproducibility. But we disagree with the NIH mandate that requires analysis of sex effects in biomedical studies. Although well intentioned, the new policy is unlikely to reduce sex/gender disparities in human neurobehavioral health while imposing a large burden on basic scientists.

In 2014, Janine Clayton and Francis Collins announced new

\footnotetext{
Received May 1, 2016; revised Sept. 2, 2016; accepted Sept. 15, 2016.

We thank Tod Kippin, Monica Oblinger, Bill Frost, Marina Wolf, and two anonymous reviewers for insightful critique.

The authors declare no competing financial interests.

Correspondence should be addressed to Dr. Lise Eliot, Department of Neuroscience, Chicago Medical School, Rosalind

Franklin University of Medicine and Science, North Chicago, IL 60064. E-mail: lise.eliot@rosalindfranklin.edu.

DOI:10.1523/JNEUROSCI.1391-16.2016

Copyright $@ 2016$ the authors $\quad 0270-6474 / 16 / 3611823-08 \$ 15.00 / 0$
}

NIH policies "that require applicants to report their plans for the balance of male and female cells and animals in preclinical studies in all future applications, unless sex-specific inclusion is unwarranted, based on rigorously defined exceptions." Like all NIH policies, the rationale is to enhance human health: Clayton and Collins (2014), for example, cite higher rates of adverse drug events in women as a primary motivation for inclusion of male and female materials in all preclinical research. The policy, to be implemented in stages, presently does not address cell culture studies but does require that sex as a biological variable (SABV) be factored into research designs, analyses, and reporting in animal studies, with limited exceptions. It further requires sex difference analyses in most studies, prescribing that researchers "develop a data analysis plan prospectively that, at a minimum, provides for the collection of data disaggregated by sex" (National Institutes of Health, 2015). Here, we focus our analysis on the broad contention underlying the policy (Sandberg and Verbalis, 2013; Clayton and Collins, 2014) and presently under discussion within the research community: that requiring inclusion of male and female animals and comparing results by sex in preclinical research will advance human health by meaningfully addressing outstanding health disparities between men and women.

A sound approach to understanding male-female health disparities requires modeling three interacting causal dimensions (Rieker and Bird, 2005): (1) factors directly related to "sex," including chromosomal complement, reproductive organs, and 
levels of gonadal hormones; (2) physiological attributes that are correlated with sex but overlap appreciably between groups of men and women, such as body size, longevity, and muscle:fat ratio; and (3) sociocultural influences that map more closely onto what we call "gender," including one's experiences, habits, selfimage, and status that result from being perceived as a man or woman. Understanding that such biological and psychosocial influences are bidirectionally entangled in humans, we have adopted throughout this commentary the term "sex/gender" when referring to male-female differences in the human brain and behavior (Kaiser et al., 2009; Springer et al., 2012).

By failing to include the second and third dimensions of sex/ gender contributions to human health, the NIH's mandate biases research and is unlikely to lead to substantial advances in the understanding and treatment of neurologic and psychiatric disorders in either women or men. This is evident even when considering the touchstone example used by advocates of the policy (Sandberg and Verbalis, 2013; Cahill, 2014; Woodruff et al., 2014): sex/gender differences related to the sleeping pill zolpidem (Ambien, Intermezzo). Postmarketing data found higher numbers of zolpidem-related adverse events in women than in men. However, subsequent analysis found that although zolpidem is cleared more slowly in nonelderly women, compared with nonelderly men (Greenblatt and Roth, 2012), differences in body weight, not sex/gender per se, mediate most of the male-female difference in human zolpidem metabolism (Greenblatt et al., 2014). Hence, the Food and Drug Administration (FDA)'s revised Drug Safety Advisory about zolpidem actually recommended a lower dose in both women and "many men" (Food and Drug Administration, 2013). More importantly, there is no evidence to support the supposition that sex differences in zolpidem side effects would have come to light from rodent studies, even if such analysis had been required at the preclinical stage. Sex differences in rodent sleep properties (Mallampalli and Carter, 2014) and in hepatic drug metabolism (Waxman and Holloway, 2009) show little resemblance to sex/gender differences in such processes in humans. Indeed, species differences overwhelm sex differences when it comes to the bioavailability of zolpidem and many other drugs (Bueters et al., 2013; Mukai et al., 2015), making animal studies a poor predictor of human pharmaceutical sex/gender differences. Finally, it is known that other sex- and gender-related factors, including higher rates of polypharmacy (National Center for Health Statistics, 2014) and greater likelihood of reporting discomfort in women, compared with men, contribute to the higher numbers of FDA reports of all adverse events in women and are recognized by the FDA as sources of bias in adverse event statistics (Food and Drug Administration, 2001).

Turning to sex/gender disparities in neurobehavioral disorders, implicit in the new NIH mandate is the assumption that comparison of male and female animals in preclinical research will provide good models for human brain-related sex/gender differences. In what follows, we argue that this claim is poorly substantiated. Furthermore, we suggest that the NIH mandate may actually hinder efforts to address sex/gender disparities in neuropsychiatric health by distorting research design and misdirecting research agendas from potentially more valuable sex/gender lines of study.

\section{Limitations of comparing brain and behavioral sex differences across species}

Any time a difference in symptoms, diagnosis, or treatment efficacy between women and men is clearly identified, it is reasonable to look for sex-related physiological mechanisms in preclinical models. But the question is: which model? Sexual dimorphism varies enormously between species, quite independently of other phylogenetic relationships. Human males and females differ modestly in average weight or height, in contrast to rats, in which adult males are $\sim 50 \%$ larger than adult females. Mice model human size dimorphism better, but their longevity sex difference is the reverse of humans.

Although all nonhuman species have limitations when extrapolating to human biology, sex difference is uniquely challenging to model in common experimental animals. As Darwin first recognized, and modern evolutionary biologists continue to elucidate, the degree of sexual dimorphism in a species is shaped by mating system, and neither rats nor mice adequately model the conditions of human sexual selection. Human mating systems are highly flexible but predominantly characterized by social monogamy and pair-bonding within extensive kinship communities that engage in biparental and alloparental care of offspring (Brown et al., 2009; Chapais, 2013). These ecological features reduce neuroanatomical sex difference compared with polygynous, uniparental species, such as laboratory rats and mice. Among primates, monogamy and pair-bonding are associated with both a dramatic increase in brain size of both sexes and a decrease in body size dimorphism between males and females (Geary, 2000; Dunbar and Shultz, 2007).

Among rodents, the effect of mating system on sexual dimorphism in the brain and behavior has been best studied through comparison of the monogamous prairie vole versus the polygynous montane and meadow voles. Male and female prairie voles form long-term socially monogamous relationships in which both parents contribute nearly equally to nurturing their young and may live in extended family groups with more than one litter (McGraw and Young, 2010). By comparison, montane and meadow voles are relatively asocial and polygynous. They do not form a partner preference and only females participate in care of the offspring, a pattern much closer to laboratory rat and mouse species. Comparison of the "sexually dimorphic nucleus" (SDN) of the medial preoptic hypothalamus (MPOA) between species reveals considerable volume difference in the polygynous montane voles but no significant difference between adult male and female prairie voles, perhaps reflecting a role of the SDN-MPOA in reproductive and social behavior (Shapiro et al., 1991; but see Campi et al., 2013). A similar relationship between mating system and brain sex difference has been observed for vole hippocampal volume, which is larger in male compared with female meadow voles, a polygynous species, but shows no sex difference in the closely related but monogamous pine voles (Jacobs et al., 1990). The dramatic contrast in brain sexual dimorphism between closely related species demonstrates how ecologically dependent brain sex differences are and highlights the difficulty of modeling human sex/gender differences in any specific experimental animal.

In its application to neuroscience, a guiding assumption behind the mandate to compare male and female animal brains is that such research provides a route for understanding sex/gender differences in human behavior and mental health. However, as leading researchers in the field of animal sex difference caution, simple extrapolation from neural sex difference to behavioral sex difference is rarely possible; even the SDN-MPOA has yet to be clearly associated with a specific behavioral or physiological role (McCarthy and Arnold, 2011; McCarthy, 2016). It is also the case that physiological sex differences often act to make behavior more similar between males and females in a particular species (de Vries, 2004). This is a key principle for understanding sex differences within a given species or strain (McCarthy et al., 2012) 
that adds considerable complexity to the mission of using animals to understand clinical sex/gender differences in humans.

Such species-specific sex effects make the choice of animal model challenging for researchers studying neuropsychiatric diseases that disparately impact women and men. For example, women are diagnosed with Alzheimer's disease at much greater rates than men (nearly $70 \%$ of the patients who die from the disease are female); however, the bulk of this disparity is due to women's greater longevity (Moschetti et al., 2012) because the greatest risk factor for Alzheimer's disease is advanced age. Greater female longevity is found among chimpanzees and most rat species, but not among mice and orangutans (Sanz et al., 2007).

Sex/gender differences in depression and anxiety have proven especially difficult to model in experimental animals. Both disorders are about twice as common in women, compared with men (Kessler, 2003; Kessler et al., 2005). However, two widely used models of depressive symptoms in rodents (immobility in the forced swim test and sucrose preference following chronic mild stress) do not replicate women's greater vulnerability; a third model, learned helplessness to uncontrollable foot or tail shock, reveals greater vulnerability in male compared with female rats. Sex/gender differences in anxiety are also opposite in sign in rats compared with humans. In most paradigms, such as the open field test, elevated plus maze, light aversion, and passive avoidance, male rats exhibit greater anxiety than females (Kokras and Dalla, 2014). Much of the difference in hiding and exploratory behavior in these assays is explained by female rats' higher physical activity level, another sex difference that is opposite in humans, in which boys and men are generally more physically active than girls and women (Eaton and Enns, 1986). Finally, experimental models of post-traumatic stress disorder (PTSD) also struggle to reproduce its higher prevalence in women (Shansky, 2015). Once exposed to trauma, women are approximately twice as likely as men to develop PTSD (Breslau, 2009). Although some rat paradigms show this pattern, male rats actually exhibit greater fear learning and retention than females in the widely used fear conditioning model (Pryce et al., 1999). Similarly, in the single prolonged stress model, male rats' fear extinction does not last as long as that of females. Poorer extinction is thought to be a corollary of PTSD, where patients are unable to adequately extinguish the memory of a highly salient stressor (Keller et al., 2015).

All of these behavioral sex inversions in rats are especially paradoxical given that anxiety and depressive disorders are thought to reflect dysregulation of the stress response system and female rats do exhibit a more reactive hypothalamic-pituitary axis than males. Then again, the evidence for a sex/gender difference in human hypothalamic-pituitary axis reactivity remains surprisingly equivocal (Bangasser and Valentino, 2014). Together, these many mismatches between rodent behavior and human diagnoses hamper the goal of using sex differences in experimental animals to better understand sex/gender disparities in human stress-related disorders. Although genetic strain and estrous cycle can be tweaked in rodents to find conditions that more closely resemble human clinical findings (Kokras and Dalla, 2014; Shansky, 2015), it seems clear that the study of stressreactive behaviors in rats and mice does not allow preclinical researchers an easy vehicle for modeling the robust sex/gender differences in human anxiety, depression, and PTSD. It is likely that the mismatch between humans and rodents with regard to sex/gender differences in anxiety and depression is due to important species and ecological differences, including the uniquely human psychosocial factors we consider next.

\section{Gender dimensions of male-female differences in the human} brain and in neurobehavioral disorders

Of all the ecological conditions that make comparison of sex/ gender differences across species challenging, human culture and its psychosocial ramifications are the most profound, and also the most poorly studied at the level of the brain. Although it is tempting to assume that animal studies provide a shortcut to elucidating the "pure" biological origins of sex/gender disparities, the fact is that such psychosocial processes interact with disease and therapeutic mechanisms across all bodily systems.

Consider sex/gender differences in pain disorders. Women exhibit higher prevalence than men for many chronic pain syndromes, including neuropathic pain, fibromyalgia, irritable bowel syndrome, musculoskeletal pain, and migraine headache (Fillingim et al., 2009). Laboratory studies of threshold and tolerance in healthy participants generally find that women are more sensitive than men to a variety of painful stimuli (Racine et al., 2012a; Bartley and Fillingim, 2013). However, it has been challenging to disentangle the various biological, psychological, and cultural contributors to these sex/gender gaps in humans (Mogil, 2012), despite recent findings implicating different cellular mechanisms of pain sensitivity in male and female mice of certain strains (Sorge et al., 2015). Neuroimaging and electroencephalography have yet to reveal a clear neural basis for sex/ gender difference in human pain processing, nor do other physiological or hormonal measures demonstrate an obvious mechanism for differences in pain threshold and tolerance (Racine et al., 2012b; Bartley and Fillingim, 2013).

On the other hand, considerable research does find that pain judgments are influenced by psychosocial factors, especially gender role expectations (Alabas et al., 2012). Women are more likely to admit pain and catastrophize it (i.e., to ruminate on the experience, magnify its impact, and feel helpless in the face of it), whereas men are likelier to adopt a stoic affect, ignoring pain and denying its impact. This difference helps explain why sex/gender differences in pain sensitivity and diagnoses do not emerge until adolescence (Fillingim et al., 2009; Schmitz et al., 2013), when youth enter a phase of amplified conformity known as gender intensification (Hill and Lynch, 1983; Galambos et al., 1990). Among adults, gender differences in pain thresholds and tolerance are often reduced or eliminated in studies that control for individual differences in anxiety, gender role endorsement, selfefficacy, and coping style (Jackson et al., 2002; Fillingim et al., 2009; Mogil, 2012). Other social variables, including cultural origin and the gender of the experimenter, also modify sex/gender differences in pain perception (Racine et al., 2012b). When it comes to clinical practice, even a leading researcher on animal sex difference concedes that analgesic treatments must always be titrated on an individual basis, where biological sex is but one of many sources of interindividual variability (Mogil, 2012).

The same applies to several psychiatric disorders with skewed sex/gender prevalence. Unipolar depression and anxiety disorders are diagnosed nearly twice as often in adult females than males (Kessler, 2003; Kessler et al., 2005). Like pain syndromes, there is no sex difference in diagnosis of these disorders in childhood, and most evidence indicates that the increase in females at puberty is less a matter of hormonal shifts than of psychosocial factors, including rumination, peer relationship stress, objectified body image, and negative life events, such as sexual harassment (Hyde et al., 2008). Indeed, the parallel emergence of sex/ gender differences in pain syndromes and mood disorders at puberty supports other evidence that depression itself may be a key factor in the female preponderance of chronic pain diagnoses 
(Mogil, 2012), as opposed to a sex/gender difference in physiological pain processing per se.

Like pain, sex/gender differences in clinical depression are influenced by psychological, social, and cultural factors that are not well modeled in animals. First, depression diagnoses are based largely on subjective responses, with men likelier to mask feelings of vulnerability and worthlessness due to social norms of masculine behavior (Addis, 2008). Second, the DSM depression criteria themselves are biased toward measuring the internalizing symptoms that are more common in women, such as crying, sadness, guilt, and fatigue. Recently, clinical researchers have developed masculine depression survey tools that include the externalizing symptoms that men are likelier to report, including irritability, anger, and substance abuse (Rice et al., 2015). When such measures are added to traditional depression survey items, the sex/gender difference in depression prevalence is eliminated (Martin et al., 2013). Given that diagnoses such as conduct disorder and substance abuse have the inverse prevalence of depression and anxiety (i.e., twice as common in men) (Kessler et al., 2005), a unifying interpretation is that men and women are similarly vulnerable to stress-related psychiatric disorders but manifest them in different ways contingent on gender norms.

Depression and anxiety are not the only psychiatric diagnoses to show a high sex/gender ratio. Attention deficit hyperactivity disorder and autism spectrum disorders are also highly skewed, in this case, diagnosed up to four times more often in male than female patients. Here again, however, there is evidence that high sex/gender ratios in both of these disorders are influenced at least in part by sociocultural factors, particularly the gender stereotypes that are embedded in diagnostic criteria used to determine who exceeds the clinical threshold (e.g., Uebel et al., 2010; Dworzynski et al., 2012).

The classic example of a cultural etiology underlying a sex/ gender-skewed psychiatric disorder is anorexia nervosa. Although often comorbid with depression and anxiety, anorexia nervosa shows a prevalence ratio of 1:10 in men:women and as high as 1:100 among 15- to 19-year-old urban, Western adolescents. Cross-national comparisons find strong evidence linking this disparity to cultural transmission caused by globalization, modernization, and media exposure promoting the Western beauty ideal (Smink et al., 2012).

Clinical researchers are increasingly recognizing the contribution of sociocultural factors to gender disparities in health and medical care outside the neuropsychiatric arena. Chapman et al. (2013) reviewed evidence that implicit bias about gender influences diagnosis rates and treatment decisions regarding several diseases. They found, for example, that women are three times less likely than men to receive knee arthroplasty when clinically appropriate, perhaps because their pain complaints are judged to be less serious than men's and women are presumed less likely to need the surgery to maintain vigorous physical activity. Other recent research has uncovered gender disparity in treatment for cardiovascular disease; compared with men of the same age, women younger than 55 years are less likely to be specifically counseled about their cardiovascular disease risk but more likely to be told to lose weight, a difference that may contribute to the higher rate of cardiovascular disease death in women (Bairey Merz et al., 2015). Independent of their biological sex, individuals with feminine roles and personality traits have poorer cardiac outcomes than more masculine individuals, revealing a surprising interaction between psychosocial gender and human cardiac function in a recent study by Pelletier et al. (2016).
Turning back to the brain, the burgeoning field of cultural neuroscience has demonstrated the influence of social attributes such as ethnicity (Han and Ma, 2014) and poverty (Hackman and Farah, 2009) on neural structure and function. A few researchers have begun probing relationships between individuals' degree of gender role endorsement and brain activation (Bourne and Maxwell, 2010) or regional brain volumes (Belfi et al., 2014). But generally speaking, the effect of gender enculturation on the brain has received scant research attention compared with the sharp focus on sex-based biology (Eliot, 2011). The new mandate contributes to this imbalance, prioritizing a broad search for biological sex factors in nonhuman animals despite profound evidence pointing to the need for deeper exploration of sociocultural factors underlying sex/gender disparities in human neurologic and behavioral health.

\section{Sex in context}

Defenders of policies requiring the study of sex in preclinical materials readily acknowledge that experimental organisms often poorly model sex/gender differences in neurological disorders. They may further concede that nonhuman organisms cannot model uniquely human gender factors. But, they ask: what are the harms of requiring study of sex as a variable in preclinical research? If we are to eventually understand sex/gender interactions, does not research on "pure" sex differences get us part way there? Could not studies of sex variables demonstrate their nonexistence or irrelevance as much as contribute to their overstatement?

Here we arrive at a central conceptual disagreement between advocates of the new mandate and many critics. A prevailing view is that "sex" and "gender" are distinct variables: "sex" is a biological variable represented by genes, gonadal hormones, and reproductive processes that may be clearly delineated as "male" and "female," whereas "gender" is a sociocultural factor referring to behaviors, expectations, and other psychological attributes of human men and women acquired through social context (National Institutes of Health, 2015). According to this view, sex can be cleanly accessed through studies of nonhuman animals, and sex factors may be expected to function in very similar ways across species and contexts. We believe that these suppositions are incorrect.

The perspective that we outline here is grounded in a different understanding of sex, as a complex biological variable with unstable meaning across species and ecologies (Fausto-Sterling, 2012; Richardson, 2013). For instance, mouse studies now find many dozens of genes that are differentially expressed by sex, in patterns that change dramatically during development, across different tissues, and in response to various environmental factors (Lowe et al., 2015). Sex is also not as binary as commonly perceived; in humans, $>25$ different genes have so far been linked to sexual development, each with its own set of variations that add up to a molecular spectrum, rather than a simple binary set of sex-defining features (Ainsworth, 2015). Additionally, in humans, sex is always and already situated in gendered social contexts: that is, pervasive systems of social roles and power that structure the embodied experiences of human males and females. According to this view, methodological rigor requires research design that interrogates any human male-female difference as potentially mediated by gendered cultural factors.

Sex-related effects, whether in animals or humans, exist within multiple entangled contexts and are often highly conditional: relevant only within specific phylogenetic, developmental, and ecological settings (Joel, 2011; Kokras and Dalla, 2014; Shors, 
2016). For example, one well-studied sex difference is that stress enhances learning for eyeblink conditioning in male rats but impairs the learning in females. However, this impairment happens only in virgin females, not when they are aged or postpartum (Shors, 2016). Furthermore, stress has the opposite effect on both rat sexes when the learning involves spatial or object memory: impairing learning in males and enhancing it in females (Luine et al., 2007). The conditional nature of sex effects and plasticity of sex determination itself (McCarthy, 2016) deeply complicate the aim of using animal findings to address human sex- and genderrelated health issues.

In animal research, sex is not, a priori, more profoundly relevant to biological outcomes than other genetic and environmental sources of variance, which include animal age, strain, diet, housing, social grouping, prenatal experience, experimenter handling, and much more (Joel, 2011; Prendergast et al., 2014). For example, few neuroscientists would deny the profound effect of environmental enrichment on the brain and behavior (e.g., van Praag et al., 2000; Nithianantharajah and Hannan, 2006), or the fact that animals' cognitive stimulation may affect the variability and generalizability of preclinical findings, but we do not expect every study to include a comparison of animals housed in enriched versus impoverished environments. Like each of these important health-related variables, sex should be targeted in specific studies shaped not by rote policy, but by hypotheses grounded in the central theories and methodologies of that field.

In humans, these conditional contexts include other interacting biological variables, such as height, body weight, hormone levels, and longevity, as well as psychosocial factors, such as status, selfefficacy, social connectedness, economic security, gender role endorsement, and sexual orientation. For example, many male-female differences in human brain imaging studies turn out to be epiphenomena of overall sexual dimorphism, not unlike the effect of body weight on zolpidem clearance. Thus, a highly publicized study using diffusion tensor imaging (DTI) in youth 8-22 years of age found statistically stronger interhemispheric connectivity in girls and stronger intrahemispheric connections in boys (Ingalhalikar et al., 2014). However, white matter pathways revealed by DTI are known to scale with overall brain size, which averages some $10 \%$ larger in males throughout life. Ingalhalikar et al. (2014) failed to include this routine correction for individual brain size in their analysis, but a nearly identical study published later that year that did (Hänggi et al., 2014) found that both the intrahemispheric and interhemispheric connectivity differences between males and females are attributable to brain size, not sex per se: that is, among men and women matched for brain size, there are no DTI connectivity differences. Similar scaling effects have been found for most other structural volumes claimed in early research to differ between men and women, but shown in large studies or meta-analyses not to differ after normalizing for brain size. Such structures include the corpus callosum, cerebellum, caudate, putamen, thalamus, hippocampus, nucleus accumbens, and cortical gray matter (Leonard et al., 2008; Fjell et al., 2009; Hänggi et al., 2014; Luders et al., 2014; Jäncke et al., 2015; Tan et al., 2016).

\section{Potential harms of the mandate}

Whether in animals or humans, sex/gender difference is a highprofile research area where primary findings quickly make their way into public discussion and both scientists and nonscientists have contributed to inflation and oversimplification of findings (Fine, 2010; Maney, 2015). The Ingalhalikar et al. (2014) study, for instance, received substantial international media coverage, often enormously extrapolated (O'Connor and Joffe, 2014).
Thus, a Wall Street Journal headline rendered the finding of boygirl differences in white matter pathways as, "Differences in how men and women think are hard-wired" (Hotz, 2013).

The perception that because sex differences in the brain are biological, they are innate or "hardwired," is stubbornly persistent in both popular and scientific discourse. Although neuroscientists understand that structural and functional brain differences can be induced by experience and neuroplasticity (Fine et al., 2013), many nonetheless default to speculation about gonadal hormones and evolution whenever they uncover sex/gender differences (Eliot, 2011; Maney, 2015). The mandate to study biological sex difference in animal studies, without an accompanying focus on sociocultural determinants of neurobehavioral sex/gender differences, will only add to this interpretive bias.

For those conducting animal research, there is no question that sex-related variables, like any number of sources of variance, are a valid concern in every type of study from the molecular to the behavioral level. But institutional policies that give sex special salience and emphasis can distort research. This argument was voiced among the 222 respondents to the NIH Request for Information (National Institutes of Health, 2015) about the proposed policy, many of whom "raised the importance of SABV in addition to and compared with other factors (examples given included age, species, breed/strain, and hormone levels)" that may influence the rigor and generalizability of preclinical research. Also of note in this public commentary was considerable concern about the cost of the new policy; $65 \%$ of respondents raised issues with budgetary implications regarding numbers of animals, personnel, time, and facilities, particularly for precious mouse mutants, leading to the more general concern that "additional required resources may slow overall scientific progress.” Despite such widespread uncertainty among animal researchers, the NIH appears not to have performed a cost analysis before implementing the policy (Clayton, 2016).

Finally, in considering the merits of this policy, it is important to note the backdrop of current pharmaceutical industry imperatives. There may be strong financial incentives to promote research that supports market-segmented "pink" and "blue" therapies for certain disorders. Just as manufacturers have learned they can augment their sales of everything from cell phones to soccer balls by marketing them in gender-coded colors, pharmaceutical companies are interested in expanding their patent opportunities by developing gender-specific drugs, even for marginal clinical benefit (Hartley, 2006). To point, a key advocacy group for expanding preclinical research on sex difference lists 14 major pharmaceutical and medical device manufacturers among its corporate partners (Society for Women's Health Research, 2016). Treating sex as a uniquely important variable, divorced from its psychosocial entanglements, uncritically embraces this market-driven approach to sex difference research while also leading to a climate of belief that can be harmful when used to support claims of intransigent cognitive and affective differences between men and women (Epstein, 2007).

In 1993, Congress authorized the much-needed NIH Revitalization Act, which requires inclusion of men and women in all research involving human subjects. We similarly support the study of sex differences and sex-related variables in targeted, welldesigned animal research. But the mandate to evaluate sex effects in every animal study, without due consideration of the limitations of such models or a companion initiative to drive research on the gender dimension of health disparities, poses a large burden on preclinical researchers while implicitly endorsing the paradigm that such disparities are largely biological in origin. 
Instead, we need greater support for research programs that analyze the interaction of biological and sociocultural factors in the genesis of sex/gender health disparities (Rieker and Bird, 2005) for disorders such as addiction, pain, anxiety and depression.

\section{Response from Dual Perspectives Companion}

Authors-Rebecca M. Shansky and Catherine S. Woolley

Eliot and Richardson offer several reasons to be skeptical that the National Institutes of Health (NIH) policy on sex as a biological variable (SABV) will lead to improved outcomes related to human brain health. By design, their view contrasts with ours. That said, there is much to agree with in their article, particularly that sex- and gender-based sociocultural factors in human experience are not modeled well in research animals and that animal models are limited in their capacity to explain sex/gender differences in human disorders. The difference in our perspectives on SABV may arise, at least partly, from different views on the role of animal studies in relation to human health.

If the goal of animal research were to directly explain human behavior, physiology, or disease, then much of what Eliot and Richardson argue would be persuasive, not only in the context of sex/gender, but in almost any context. However, an alternative view (one that we ascribe to) is that a principal goal of animal research is to understand how biological systems are organized and how they function, both in their baseline state and in response to controlled manipulations (including those that model aspects of disease). In this way, animal research contributes indirectly to improving human health by providing information and ideas that feed the pipeline leading to translational and clinical studies that are directly related to human disease.

A point of contention is whether it is reasonable for NIH to have targeted a policy on sex, as opposed to other variables that influence biological systems. For example, as Eliot and Richardson point out, age and genetic variations associated with strain (or manipulations, such as diet, handling, housing conditions, etc.) also could influence outcomes. Our view is that the profound underrepresentation of females in basic neuroscience studies, in parallel with compelling examples of sex differences in fundamental aspects of brain function, do justify a policy focused on sex as a variable in animal research. It is not that sex necessarily is more important than other variables, but that the potential influences of sex have been understudied in the absence of an NIH mandate.

Finally, a clarification about the NIH policy: As Janine Clayton, Director of the Office on Research for Women's Health, wrote last year for the FASEB Journal, "Considering SABV is not the same as looking for sex differences" (Clayton, 2016). Rather, the directive is for animal researchers to study both sexes and attend to which data come from which sex so that the answers to scientific questions will be known in both sexes. In some cases, initial results may justify investment of additional resources that would be required to test for sex effects; in other cases, there will be little reason to do this. Either way, we believe that the inclusion of data about biological sex will result in a stronger basic science pipeline that, in turn, will better inform the design and interpretation of studies that directly address human health questions.

\section{Reference}

Clayton JA (2016) Studying both sexes: a guiding principle for biomedicine. FASEB J 30:519-524. 10.1096/fj.15-279554 26514164

\section{References}

Addis ME (2008) Gender and depression in men. Clin Psychol 15:153 168. Ainsworth C (2015) Sex redefined. Nature 518:288-291. CrossRef Medline Alabas OA, Tashani OA, Tabasam G, Johnson MI (2012) Gender role affects experimental pain responses: a systematic review with meta-analysis. Eur J Pain 16:1211-1223. CrossRef Medline

Bairey Merz CN, Andersen HS, Shufelt CL (2015) Gender, cardiovascular disease, and the sexism of obesity. J Am Coll Cardiol 66:1958-1960. CrossRef Medline

Bangasser DA, Valentino RJ (2014) Sex differences in stress-related psychiatric disorders: neurobiological perspectives. Front Neuroendocrinol 35: 303-319. CrossRef Medline

Bartley EJ, Fillingim RB (2013) Sex differences in pain: a brief review of clinical and experimental findings. Br J Anaesth 111:52-58. CrossRef Medline

Belfi AM, Conrad AL, Dawson J, Nopoulos P (2014) Masculinity/femininity predicts brain volumes in normal healthy children. Dev Neuropsychol 39:25-36. CrossRef Medline

Bourne VJ, Maxwell AM (2010) Examining the sex difference in lateralisation for processing facial emotion: does biological sex or psychological gender identity matter? Neuropsychologia 48:1289-1294. CrossRef Medline

Breslau N (2009) The epidemiology of trauma, PTSD, and other posttrauma disorders. Trauma Violence Abuse 10:198-210. CrossRef Medline

Brown GR, Laland KN, Mulder MB (2009) Bateman's principles and human sex roles. Trends Ecol Evol 24:297-304. CrossRef Medline

Bueters T, Juric S, Sohlenius-Sternbeck AK, Hu Y, Bylund J (2013) Rat poorly predicts the combined non-absorbed and presystemically metabolized fractions in the human. Xenobiotica 43:607-616. CrossRef Medline

Cahill L (2014) Equal $\neq$ the same: sex differences in the human brain. Cerebrum 2014:5. Medline

Campi KL, Jameson CE, Trainor BC (2013) Sexual dimorphism in the brain of the monogamous California mouse (Peromyscus californicus). Brain Behav Evol 81:236-249. CrossRef Medline

Chapais B (2013) Monogamy, stronglybonded groups, and the evolution of human social structure. Evol Anthropol 22:52-65. CrossRef Medline

Chapman EN, Kaatz A, Carnes M (2013) Physicians and implicit bias: how doctors may unwittingly perpetuate health care disparities. J Gen Intern Med 28:1504-1510. CrossRef Medline

Clayton JA (2016) Studying both sexes: a guiding principle for biomedicine. FASEB J 30:519-524. CrossRef Medline

Clayton JA, Collins FS (2014) Policy: NIH to balance sex in cell and animal studies. Nature 509:282-283. CrossRef Medline

de Vries GJ (2004) Minireview. Sex differences in adult and developing brains: compensation, compensation, compensation. Endocrinology 145: 1063-1068. CrossRef Medline

Dunbar RI, Shultz S (2007) Evolution in the social brain. Science 317:13441347. CrossRef Medline

Dworzynski K, Ronald A, Bolton P, Happé F (2012) How different are girls and boys above and below the diagnostic threshold for autism spectrum disorders? J Am Acad Child Adolesc Psychiatry 51:788-797. CrossRef Medline

Eaton WO, Enns LR (1986) Sex differences in human motor activity level. Psychol Bull 100:19-28. Medline

Eliot L (2011) The trouble with sex differences. Neuron 72:895-898. CrossRef Medline

Epstein S (2007) Inclusion: the politics of difference in medical research, pp 233-257. Chicago: University of Chicago.

Fausto-Sterling A (2012) Sex/gender: biology in a social world. New York: Routledge.

Fillingim RB, King CD, Ribeiro-Dasilva MC, Rahim-Williams B, Riley JL 3rd 
(2009) Sex, gender, and pain: a review of recent clinical and experimental findings. J Pain 10:447-485. CrossRef Medline

Fine C (2010) From scanner to sound bite: issues in interpreting and reporting sex differences in the brain. Curr Dir Psychol Sci 19:280-283.

Fine C, Jordan-Young R, Kaiser A, Rippon G (2013) Plasticity, plasticity, plasticity and the rigid problem of sex. Trends Cogn Sci 17:550-551. CrossRef Medline

Fjell AM, Westlye LT, Amlien I, Espeseth T, Reinvang I, Raz N, Agartz I, Salat DH, Greve DN, Fischl B, Dale AM, Walhovd KB (2009) Minute effects of sex on the aging brain: a multisample magnetic resonance imaging study of healthy aging and Alzheimer's disease. J Neurosci 29:8774-8783. CrossRef Medline

Food and Drug Administration (2001) Comments on the General Accounting Office Draft Report, Drug Safety: Most Drugs Withdrawn in recent Years Had Greater Health Risks for Women. GAO 01-286R.

Food and Drug Administration (2013) Drug Safety Communication: Risk of next-morning impairment after use of insomnia drugs; FDA requires lower recommended doses for certain drugs containing zolpidem (ambien, ambien CR, edluar, and zolpimist). MedWatch Online 2016:6.

Galambos NL, Almeida DM, Petersen AC (1990) Masculinity, femininity, and sex role attitudes in early adolescence: exploring gender intensification. Child Dev 61:1905-1914. CrossRef Medline

Geary DC (2000) Evolution and proximate expression of human paternal investment. Psychol Bull 126:55-77. CrossRef Medline

Greenblatt DJ, Roth T (2012) Zolpidem for insomnia. Expert Opin Pharmacother 13:879-893. CrossRef Medline

Greenblatt DJ, Harmatz JS, Singh NN, Steinberg F, Roth T, Moline ML, Harris SC, Kapil RP (2014) Gender differences in pharmacokinetics and pharmacodynamics of zolpidem following sublingual administration. J Clin Pharmacol 54:282-290. CrossRef Medline

Hackman DA, Farah MJ (2009) Socioeconomic status and the developing brain. Trends Cogn Sci 13:65-73. CrossRef Medline

Han S, Ma Y (2014) Cultural differences in human brain activity: a quantitative meta-analysis. Neuroimage 99:293-300. CrossRef Medline

Hänggi J, Fovenyi L, Liem F, Meyer M, Jäncke L (2014) The hypothesis of neuronal interconnectivity as a function of brain size: a general organization principle of the human connectome. Front Hum Neurosci 8:915. CrossRef Medline

Hartley H (2006) The 'pinking' of Viagra culture: drug industry efforts to create and repackage sex drugs for women. Sexualities 9:363-378. CrossRef

Hill JP, Lynch ME (1983) The intensification of gender-related role expectations during early adolescence. In: Girls at puberty (Brooks-Gunn J, Peterson AC, eds), pp 201-228. New York: Springer.

Hotz RL (2013) Differences in how men and women think are hard-wired. Wall Street J, Dec. 9, 2013.

Hyde JS, Mezulis AH, Abramson LY (2008) The ABCs of depression: integrating affective, biological, and cognitive models to explain the emergence of the gender difference in depression. Psychol Rev 115:291-313. CrossRef Medline

Ingalhalikar M, Smith A, Parker D, Satterthwaite TD, Elliott MA, Ruparel K, Hakonarson H, Gur RE, Gur RC, Verma R (2014) Sex differences in the structural connectome of the human brain. Proc Natl Acad Sci U S A 111:823-828. CrossRef Medline

Jackson T, Iezzi T, Gunderson J, Nagasaka T, Fritch A (2002) Gender differences in pain perception: the mediating role of self-efficacy beliefs. Sex Roles 47:561-568. CrossRef Medline

Jacobs LF, Gaulin SJ, Sherry DF, Hoffman GE (1990) Evolution of spatial cognition: sex-specific patterns of spatial behavior predict hippocampal size. Proc Natl Acad Sci U S A 87:6349-6352. CrossRef Medline

Jäncke L, Mérillat S, Liem F, Hänggi J (2015) Brain size, sex, and the aging brain. Hum Brain Mapp 36:150-169. CrossRef Medline

Joel D (2011) Male or female? Brains are intersex. Front Integr Neurosci 5:1-5. Medline

Kaiser A, Haller S, Schmitz S, Nitsch C (2009) On sex/gender related similarities and differences in fMRI language research. Brain Res Rev 61:4959. CrossRef Medline

Keller SM, Schreiber WB, Staib JM, Knox D (2015) Sex differences in the single prolonged stress model. Behav Brain Res 286:29-32. CrossRef Medline

Kessler RC (2003) Epidemiology of women and depression. J Affect Disord 74:5-13. CrossRef Medline
Kessler RC, Berglund P, Demler O, Jin R, Merikangas KR, Walters EE (2005) Lifetime prevalence and age-of-onset distributions of DSM-IV disorders in the national comorbidity survey replication. Arch Gen Psychiatry 62: 593-602. CrossRef Medline

Kokras N, Dalla C (2014) Sex differences in animal models of psychiatric disorders. Br J Pharmacol 171:4595-4619. CrossRef Medline

Leonard CM, Towler S, Welcome S, Halderman LK, Otto R, Eckert MA, Chiarello C (2008) Size matters: cerebral volume influences sex differences in neuroanatomy. Cereb Cortex 18:2920-2931. CrossRef Medline

Lowe R, Gemma C, Rakyan VK, Holland ML (2015) Sexually dimorphic gene expression emerges with embryonic genome activation and is dynamic throughout development. BMC Genomics 16:295. CrossRef Medline

Luders E, Toga AW, Thompson PM (2014) Why size matters. Differences in brain volume account for apparent sex differences in callosal anatomy: the sexual dimorphism of the corpus callosum. Neuroimage 84:820-824. CrossRef Medline

Luine VN, Beck KD, Bowman RE, Frankfurt M, Maclusky NJ (2007) Chronic stress and neural function: accounting for sex and age. J Neuroendocrinol 19:743-751. CrossRef Medline

Mallampalli MP, Carter CL (2014) Exploring sex and gender differences in sleep health: a Society for Women's Health Research Report. J Womens Health (Larchmt) 23:553-562. CrossRef Medline

Maney DL (2015) Just like a circus: the public consumption of sex differences. Curr Top Behav Neurosci 19:279-296. CrossRef Medline

Martin LA, Neighbors HW, Griffith DM (2013) The experience of symptoms of depression in men vs women: analysis of the national comorbidity survey replication. JAMA Psychiatry 70:1100-1106. CrossRef Medline

McCarthy MM (2016) Multifaceted origins of sex differences in the brain. Philos Trans R Soc Lond B Biol Sci 371:20150106. CrossRef Medline

McCarthy MM, Arnold AP (2011) Reframing sexual differentiation of the brain. Nat Neurosci 14:677-683. CrossRef Medline

McCarthy MM, Arnold AP, Ball GF, Blaustein JD, de Vries GJ (2012) Sex differences in the brain: the not so inconvenient truth. J Neurosci 32: 2241-2247. CrossRef Medline

McGraw LA, Young LJ (2010) The prairie vole: an emerging model organism for understanding the social brain. Trends Neurosci 33:103-109. CrossRef Medline

Mogil JS (2012) Sex differences in pain and pain inhibition: multiple explanations of a controversial phenomenon. Nat Rev Neurosci 13:859-866. CrossRef Medline

Moschetti K, Cummings PL, Sorvillo F, Kuo T (2012) Burden of Alzheimer's disease-related mortality in the united states, 1999-2008. J Am Geriatr Soc 60:1509-1514. CrossRef Medline

Mukai M, Isobe T, Okada K, Murata M, Shigeyama M, Hanioka N (2015) Species and sex differences in propofol glucuronidation in liver microsomes of humans, monkeys, rats and mice. Pharmazie 70:466-470. CrossRef Medline

National Center for Health Statistics (2014) Health, United States, 2013: with special feature on prescription drugs. Hyattsville, MD: National Center for Health Statistics.

National Institutes of Health (2015) Consideration of sex as a biological variable in NIH-funded research. Bethesda, MD: National Institutes of Health.

Nithianantharajah J, Hannan AJ (2006) Enriched environments, experience-dependent plasticity and disorders of the nervous system. Nat Rev Neurosci 7:697-709. CrossRef Medline

O'Connor C, Joffe H (2014) Gender on the brain: a case study of science communication in the new media environment. PLoS One 9:e110830. CrossRef Medline

Pelletier R, Khan NA, Cox J, Daskalopoulou SS, Eisenberg MJ, Bacon SL, Lavoie KL, Daskupta K, Rabi D, Humphries KH, Norris CM, Thanassoulis G, Behlouli H, Pilote L (2016) Sex versus gender-related characteristics: which predicts outcome after acute coronary syndrome in the young? J Am Coll Cardiol 67:127-135. CrossRef Medline

Prendergast BJ, Onishi KG, Zucker I (2014) Female mice liberated for inclusion in neuroscience and biomedical research. Neurosci Biobehav Rev 40:1-5. CrossRef Medline

Pryce CR, Lehmann J, Feldon J (1999) Effect of sex on fear conditioning is similar for context and discrete CS in Wistar, Lewis and Fischer rat strains. Pharmacol Biochem Behav 64:753-759. CrossRef Medline

Racine M, Tousignant-Laflamme Y, Kloda LA, Dion D, Dupuis G, Choinière 
M (2012a) A systematic literature review of 10 years of research on sex/ gender and experimental pain perception: 1 . Are there really differences between women and men? Pain 153:602-618. CrossRef Medline

Racine M, Tousignant-Laflamme Y, Kloda LA, Dion D, Dupuis G, Choinière M (2012b) A systematic literature review of 10 years of research on sex/ gender and pain perception; 2. Do biopsychosocial factors alter pain sensitivity differently in women and men? Pain 153:619-635. CrossRef Medline

Rice SM, Fallon BJ, Aucote HM, Möller-Leimkuhler A, Treeby MS, Amminger GP (2015) Longitudinal sex differences of externalising and internalising depression symptom trajectories: implications for assessment of depression in men from an online study. Int J Soc Psychiatry 61:236240. CrossRef Medline

Richardson SS (2013) Sex itself: the search for male and female in the human genome. Chicago: University of Chicago.

Rieker PP, Bird CE (2005) Rethinking gender differences in health: why we need to integrate social and biological perspectives. J Gerontol 60B:4047. Medline

Sandberg K, Verbalis JG (2013) Sex and the basic scientist: is it time to embrace title IX? Biol Sex Differ 4:13. CrossRef Medline

Sanz A, Hiona A, Kujoth GC, Seo AY, Hofer T, Kouwenhoven E, Kalani R, Prolla TA, Barja G, Leeuwenburgh C (2007) Evaluation of sex differences on mitochondrial bioenergetics and apoptosis in mice. Exp Gerontol 42:173-182. CrossRef Medline

Schmitz AK, Vierhaus M, Lohaus A (2013) Pain tolerance in children and adolescents: sex differences and psychosocial influences on pain threshold and endurance. Eur J Pain 17:124-131. CrossRef Medline

Shansky RM (2015) Sex differences in PTSD resilience and susceptibility: challenges for animal models of fear learning. Neurobiol Stress 1:60-65. CrossRef Medline

Shapiro LE, Leonard CM, Sessions CE, Dewsbury DA, Insel TR (1991) Comparative neuroanatomy of the sexually dimorphic hypothalamus in monogamous and polygamous voles. Brain Res 541:232-240. CrossRef Medline
Shors TJ (2016) A trip down memory lane about sex differences in the brain. Philos Trans R Soc Lond B Biol Sci 371:1-11. CrossRef Medline

Smink FR, van Hoeken D, Hoek HW (2012) Epidemiology of eating disorders: incidence, prevalence and mortality rates. Curr Psychiatry Rep 14: 406-414. CrossRef Medline

Society for Women's Health Research (2016) Corporate advisory council. Washington, DC: Society for Women's Health Research.

Sorge RE, Mapplebeck JC, Rosen S, Beggs S, Taves S, Alexander JK, Martin LJ, Austin JS, Sotocinal SG, Chen D, Yang M, Shi XQ, Huang H, Pillon NJ, Bilan PJ, Tu Y, Klip A, Ji RR, Zhang J, Salter MW, et al. (2015) Different immune cells mediate mechanical pain hypersensitivity in male and female mice. Nat Neurosci 18:1081-1083. CrossRef Medline

Springer KW, Mager Stellman J, Jordan-Young RM (2012) Beyond a catalogue of differences: a theoretical frame and good practice guidelines for researching sex/gender in human health. Soc Sci Med 74:1817-1824. CrossRef Medline

Tan A, Ma W, Vira A, Marwha D, Eliot L (2016) The human hippocampus is not sexually-dimorphic: meta-analysis of structural MRI volumes. Neuroimage 124:350-366. CrossRef Medline

Uebel H, Albrecht B, Asherson P, Börger NA, Butler L, Chen W, Christiansen H, Heise A, Kuntsi J, Schäfer U, Andreou P, Manor I, Marco R, Miranda A, Mulligan A, Oades RD, van der Meere J, Faraone SV, Rothenberger A, Banaschewski T (2010) Performance variability, impulsivity errors and the impact of incentives as gender-independent endophenotypes for ADHD. J Child Psychol Psychiatry 51:210-218. CrossRef Medline

van Praag H, Kempermann G, Gage FH (2000) Neural consequences of environmental enrichment. Nat Rev Neurosci 1:191-198. CrossRef Medline

Waxman DJ, Holloway MG (2009) Sex differences in the expression of hepatic drug metabolizing enzymes. Mol Pharmacol 76:215-228. CrossRef Medline

Woodruff TK, Kibbe MR, Paller AS, Turek FW, Woolley CS (2014) Commentary: "Leaning in" to support sex differences in basic science and clinical research. Endocrinology 155:1181-1183. CrossRef Medline 